\title{
Regional differences in mental health in Great Britain
}

\author{
Glyn Lewis, Margaret Booth
}

\begin{abstract}
Study objective-The aim was to study the pattern and magnitude of regional differences in psychiatric morbidity and compare these with regional differences in all cause mortality.

Design-The study was a secondary analysis of data from a cross sectional survey. The main outcome was the prevalence of psychiatric morbidity. This was assessed using the general health questionnaire, a self administered measure of neurotic symptoms.
\end{abstract}

Setting-England, Wales and Scotland.

Participants-9003 adults were selected from the electoral register.

Main results-The prevalence of psychiatric morbidity was $31 \%$ with a statistically significant difference between the regions $(p=0.006)$. All four northern regions of England had a higher prevalence of psychiatric morbidity than the four southern regions. These differences were comparable in size to the regional differences in all cause mortality. Scotland had low psychiatric morbidity but high all cause mortality while Greater London had high psychiatric morbidity but low mortality. Regional variation in psychiatric morbidity was less marked within social classes I and II and among those living in urban areas.

Conclusions-Psychiatric morbidity is common and is an important public health problem. Regions with relatively high psychiatric morbidity did not always have relatively high mortality. Knowledge of the causes of these regional differences could ultimately lead to preventive action and be important when distributing health service resources.

f Epidemiol Community Health 1992; 46: 608-611

Institute of Psychiatry, De Crespigny Park, London SE5 8AF, United Kingdom G Lewis

Department of

Epidemiology and

Population Sciences London School of Hygiene and Tropical Medicine, Keppel

Street, London WC1, United Kingdom M Booth

Correspondence to: Dr Lewis

Accepted for publication Accepted 1992
Regional variation in health may result from preventable environmental causes and can form the basis for public health interventions. ${ }^{1-3}$ The study of regional differences within Britain has also provided a basis for distributing National Health Service resources as a result of the Resource Allocation Working Party (RAWP). ${ }^{4}$ Many previous studies on regional inequalities in Britain have concentrated on mortality. ${ }^{1}$ Importance is now being attached to subjective assessments of health and measures of morbidity because they measure personal wellbeing and predict use of health services. ${ }^{5-7}$

Research over the last 30 years has established that neurotic symptoms, particularly anxiety and depression, are the commonest manifestations of poor mental health in the general population. ${ }^{89}$ Methods of measuring such morbidity include the use of self administered questionnaires such as the general health questionnaire (GHQ). ${ }^{10}$ The GHQ has been used in a variety of circumstances and cultures and the results have been shown to agree closely with those of standardised assessments conducted by psychiatrists. ${ }^{11}$

Psychiatric morbidity is of major importance for public health. It is common and prevalence estimates vary between $20 \%$ and $30 \% .{ }^{9}$ It is expensive, as $40 \%$ of sickness absence can be attributed to psychiatric morbidity ${ }^{12} 13$ resulting in an overall cost of $£ 6$ billion per year in the UK (1985 prices). ${ }^{14}$ Thus neurotic symptoms result in costs three to four times those of schizophrenia, ${ }^{15}{ }^{16}$ and probably lead to more lost production than cardiovascular disease because they affect a younger age group. Psychiatric morbidity also leads to the use of health services. About $20 \%$ of general practitioner consultations can be attributed to psychiatric morbidity ${ }^{6}$ though about half of attenders with psychiatric morbidity present general practitioners with physical symptoms. ${ }^{17}$

The present study was designed to examine the prevalence of psychiatric morbidity measured using the GHQ, and to study differences in mental health between the British regions. The results were then compared with regional all cause mortality. Finally, explanatory factors for the regional differences in the prevalence of psychiatric morbidity were explored.

\section{Methods}

The study used data collected in the health and lifestyle survey between 1984 and July 1985, and details of the method have already been described. ${ }^{18}$ The study population was selected using a three stage design. Within standard regions of England, Wales, and Scotland parliamentary constituencies were allocated to one of three population density bands, and 198 constituencies were then selected with probability proportional to the size of the electorate. Two wards were selected from each, again with probability proportional to the electorate. In each household one individual aged 18 years or over was selected from all those resident, using random numbers. A total of 12254 addressess provided interviews with 9003 individuals.

Information was collected at two home visits and on the second visit the respondents were given the 30 item GHQ and asked to complete and return it to the survey organisation.

Those who completed and returned the GHQ comprised the sample for this study. Using the 
address of each respondent, the sample was subdivided by region of residence (Scotland, Wales, and the eight standard regions of England). Greater London and the South East excluding Greater London were considered as two distinct regions.

As is customary, the prevalence of psychiatric morbidity was defined as the percentage scoring 5 or more on the GHQ. A score of 5 corresponds approximately to the point at which a primary care doctor would recognise a significant degree of psychiatric morbidity.

Variables from the personal interview selected for analysis because of their possible association with psychiatric morbidity were sex, age, marital status, and social class, classified according to the Registrar General's 1980 classification, ${ }^{19}$ with married and widowed women classified by husband's occupation, and single and divorced women by own occupation. Those who said they were unemployed and "actively seeking work" were classified as unemployed. The living environment around the respondent's home was classified into three categories: urban area without access to garden or open space; urban area with adjacent open space or large garden, and country district. Subjects who reported any "long standing illness, disability or infirmity" which limited their activities "in any way compared with people of your own age" were deemed as having a chronic illness.

Using the prevalence of psychiatric morbidity in the sample residing in England and Wales as the standard, age and sex standardised prevalence ratios (SPR) for psychiatric morbidity were calculated for the 11 regions. Ninety five per cent confidence intervals were calculated using the normal approximation to the binomial and assuming that the expected proportion did not vary. Using England and Wales rates as the standard, age and sex standardised mortality ratios (SMR) and $95 \%$ confidence intervals ${ }^{20}$ for all cause mortality were calculated for the 11 regions using published data provided by OPCS ${ }^{21}$ for 1984 and the Scottish Office ${ }^{22}$ for 1985.

Odds ratios for psychiatric morbidity, together with their $95 \%$ confidence intervals and tests for heterogeneity were computed by logistic regression techniques using the EGRET statistical package. ${ }^{23}$ Attempts to explain observed differences were made by adjusting the odds ratios for the factors associated with psychiatric morbidity.

\section{Results}

The GHQ was returned by 6572 respondents, $53.6 \%$ of the original sample and $73 \%$ of the interviewed sample. There were statistically significant differences in the response rate between the regions $\left(\chi^{2}=104 \cdot 5, \mathrm{df}=10\right.$, $p<0.001)$. Greater London had the lowest response rate $(43 \%)$ and, in general, the southern regions had a higher response rate than the northern regions (see Cox et $a l^{18}$ ).

Table I shows the regional variation in the variables associated with psychiatric morbidity. The northern regions and Scotland, with few exceptions, had more respondents in social classes IV and V, who were unemployed, and who lived in built up areas. Greater London had the highest percentage of subjects who lived in built up areas. Although small, the regional differences in all the variables were statistically significant.

The prevalence of psychiatric morbidity in the sample as a whole was $31 \%$. The prevalence by region is shown in table II. All four northern regions had a higher prevalence of psychiatric morbidity than the four southern regions. The prevalence of psychiatric morbidity ranged from $27 \%$ in the East Midlands Region to $37 \%$ in the north. Scotland had relatively good mental health with a prevalence of $28 \%$ while Greater London had relatively poor mental health with a prevalence of $35 \%$. The differences in the prevalence of psychiatric morbidity between the 11 regions were statistically significant $\left(\chi^{2}=24.9, \mathrm{df}=10, \mathrm{p}=0.006\right)$.

Table II also shows that all four northern regions had raised SPRs for psychiatric morbidity and raised all cause SMRs while the four southern regions had lowered SPRs and SMRs. For example, the north had an SPR of 116 and an SMR of 113 while for East Anglia the SPR was 92 and SMR 91. Greater London had a high SPR (112) but a low SMR (95). Scotland had the highest SMR (115) but one of the lowest SPRs for psychiatric morbidity (90). The East Midlands Region had a notably higher SMR (99) than SPR (87). The regional differences in the prevalence of psychiatric morbidity were comparable in size to the regional differences in mortality.

Because of the similarity in the prevalence of psychiatric morbidity within the four northern regions and within the four southern regions, and to aid interpretation of the results, subsequent analyses are presented with data for the four
Table I Regional variation in variables associated with psychiatric morbidity.

\begin{tabular}{|c|c|c|c|c|c|c|c|c|}
\hline & $\begin{array}{l}\text { Sample } \\
\text { size }\end{array}$ & $\stackrel{\%}{\text { Female }}$ & $\begin{array}{l}\% \text { in } \\
\text { Social class } \\
I V \& V\end{array}$ & $\begin{array}{l}\%> \\
65 \text { years }\end{array}$ & ${ }_{D i v W S^{a}}$ & $\begin{array}{l}\text { o Living in } \\
\text { built up } \\
\text { urban area }\end{array}$ & $\begin{array}{l}\% \\
\text { Unemployed }\end{array}$ & $\begin{array}{l}\text { \% With } \\
\text { chronic illness }\end{array}$ \\
\hline $\begin{array}{l}\text { Southern regions: } \\
\text { East Midlands } \\
\text { East Anglia } \\
\text { South West } \\
\text { South East }\end{array}$ & $\begin{array}{r}519 \\
270 \\
534 \\
1260\end{array}$ & $\begin{array}{l}56 \\
59 \\
55 \\
55\end{array}$ & $\begin{array}{l}20 \\
24 \\
20 \\
18\end{array}$ & $\begin{array}{l}19 \\
17 \\
23 \\
24\end{array}$ & $\begin{array}{l}14 \\
11 \\
15 \\
12\end{array}$ & $\begin{array}{l}29 \\
10 \\
35 \\
20\end{array}$ & $\begin{array}{l}4 \cdot 7 \\
1.5 \\
2.8 \\
2.6\end{array}$ & $\begin{array}{l}17 \\
17 \\
18 \\
14\end{array}$ \\
\hline $\begin{array}{l}\text { Northern regions } \\
\text { North } \\
\text { North West } \\
\text { West Midlands } \\
\text { Yorkshire/Humberside }\end{array}$ & $\begin{array}{r}407 \\
780 \\
571 \\
\text { le } 594\end{array}$ & $\begin{array}{l}61 \\
61 \\
56 \\
57\end{array}$ & $\begin{array}{l}29 \\
25 \\
23 \\
26\end{array}$ & $\begin{array}{l}18 \\
17 \\
18 \\
19\end{array}$ & $\begin{array}{l}17 \\
16 \\
15 \\
17\end{array}$ & $\begin{array}{l}37 \\
34 \\
41 \\
35\end{array}$ & $\begin{array}{l}7.4 \\
6.4 \\
7.5 \\
6 \cdot 4\end{array}$ & $\begin{array}{l}22 \\
16 \\
18 \\
17\end{array}$ \\
\hline Greater London & 639 & 53 & 18 & 17 & 16 & 59 & 5.0 & 19 \\
\hline Wales & 349 & 57 & 28 & 14 & 13 & 30 & $5 \cdot 2$ & 14 \\
\hline \multirow[t]{2}{*}{ Scotland } & 649 & 56 & 26 & 17 & 15 & 42 & $6 \cdot 3$ & 14 \\
\hline & $\begin{array}{l}\chi^{2} \\
\mathrm{df} \\
\mathrm{p}\end{array}$ & $\begin{array}{l}19 \cdot 7 \\
10 \\
0.03\end{array}$ & $\begin{array}{l}161 \cdot 5 \\
20 \\
<0.0001\end{array}$ & $\begin{array}{l}69 \cdot 6 \\
30 \\
<0.0001\end{array}$ & $\begin{array}{l}88.0 \\
20 \\
<0.0001\end{array}$ & $\begin{array}{l}961 \cdot 2 \\
20 \\
<0.0001\end{array}$ & $\begin{array}{l}63.5 \\
10 \\
<0.0001\end{array}$ & $\begin{array}{l}31 \cdot 9 \\
10 \\
<0.0001\end{array}$ \\
\hline
\end{tabular}


Table II Percentage of respondents with psychiatric morbidity, standardised prevalence ratios (SPR) for psychiatric morbidity, and standardised all cause mortality ratios (SMR) by region.

\begin{tabular}{llll}
\hline & $\begin{array}{l}\text { oo Respondents } \\
\text { with psychiatric } \\
\text { morbidity }\end{array}$ & $S P R(95 \%$ CI $)$ & $S M R(95 \% C I)$ \\
\hline $\begin{array}{l}\text { Southern regions } \\
\text { East Midlands }\end{array}$ & $26 \cdot 8$ & $87(74-99)$ & $99(98-100)$ \\
$\quad$ East Anglia & $28 \cdot 5$ & $92(75-109)$ & $91(90-92)$ \\
$\quad \begin{array}{l}\text { South West } \\
\text { South East }\end{array}$ & $30 \cdot 1$ & $96(84-109)$ & $91(90-92)$ \\
$\quad$ Northern regions & $29 \cdot 1$ & $94(86-102)$ & $92(92-93)$ \\
$\quad$ North & $36 \cdot 9$ & $116(101-131)$ & $113(112-115)$ \\
$\quad$ North West & $32 \cdot 8$ & $105(94-115)$ & $111(110-112)$ \\
West Midlands & $33 \cdot 6$ & $108(95-120)$ & $105(104-105)$ \\
$\quad$ Yorks/Humberside & $32 \cdot 8$ & $105(93-117)$ & $106(105-106)$ \\
$\quad$ Greater London & $35 \cdot 1$ & $112(101-112)$ & $95(94-96)$ \\
Wales & $31 \cdot 2$ & $101(85-116)$ & $101(100-102)$ \\
Scotland & $28 \cdot 2$ & $90(79-101)$ & $115(113-116)$ \\
\hline
\end{tabular}

$\overline{C I}=$ confidence interval northern regions combined and the four southern regions combined.

Table III shows that there was less variation in psychiatric morbidity between the regions in social class I and II as compared to the other social classes (heterogeneity: $\chi^{2}=14 \cdot 8, \mathrm{df}=8, \mathrm{p}=0.06$ ). In particular the north to south difference was eliminated within social classes I and II. There was also a suggestion that the regional differences were less marked within urban areas without access to open spaces (heterogeneity: $\chi^{2}=10 \cdot 9$, $\mathrm{df}=4, \mathrm{p}=0.03)$. The odds ratio for psychiatric morbidity in the northern regions (compared to the southern regions) was only 1.06 in urban areas without access to open spaces while it was 1.24 in urban areas with access to open spaces and 1.29 in country districts.

Table IV gives the odds ratios for psychiatric morbidity, by region, before and after adjustment for the variables found to be associated with psychiatric morbidity. There was no statistically significant difference in the prevalence of psychiatric morbidity between the regions after adjustment $\left(\chi^{2}=7 \cdot 46, \mathrm{df}=4, \mathrm{p}=0 \cdot 11\right)$. The factors which contributed most to the reduction in the regional differences were social class and living environment.

\section{Discussion}

The results show regional differences in the prevalence of psychiatric morbidity of a similar magnitude and pattern to regional differences for all cause mortality. The northern regions of Britain had a higher prevalence of psychiatric morbidity and a higher mortality than the southern regions. There were two exceptions, however, as Scotland had relatively good mental health in contrast to its high all cause mortality and Greater London had relatively poor mental health in comparison to the SMR.

The response rate, $54 \%$ of the original sample and which differed between the regions, is a possible source of bias. However, there is evidence that those with psychiatric disorders are less likely to respond to postal surveys. ${ }^{2425}$ The probable direction of the bias is therefore to underestimate the prevalence of psychiatric morbidity and so to underestimate the regional differences.

Despite the encouraging results of validity studies ${ }^{11}$ there is some suggestion that those with disabling conditions score more highly on the GHQ when compared with a psychiatric interview. However, adjusting for chronic illness did not substantially affect the regional differences. In addition, it is conceivable that cultural differences between the regions may have affected the interpretation or the perceived social desirability of responses to the GHQ.

The analysis has classified subjects into those with and those without psychiatric morbidity, although it is more reasonable to conceive of psychiatric morbidity along a continuum of severity. ${ }^{26}$ The analysis was conducted in order to enable regional mental health to be compared with regional all cause mortality. There is no reason to expect that a different method of analysis, using psychiatric morbidity as a continuous variable, would lead to different results. ${ }^{27}$

There was some evidence to suggest that the regional differences between the northern and southern regions were less marked within social classes I and II and within built up urban areas. These results have to be interpreted with caution as neither hypothesis was formulated before analysis and the statistical significance was borderline. However, both results have some intuitive

Table IV Odds Ratios (95\% confidence interval) for psychiatric morbidity by region; before and after adjustment for the variables associated with psychiatric morbidity ${ }^{a}$.

\begin{tabular}{lll}
\hline & Unadjusted & $\begin{array}{l}\text { Adjusted for } \\
\text { all variables }^{a}\end{array}$ \\
\hline Southern regions & $1 \cdot 00^{b}$ & $1 \cdot 00^{b}$ \\
Northern regions & $1 \cdot 25(1 \cdot 10-1 \cdot 41)$ & $1 \cdot 11(0 \cdot 98-1 \cdot 27)$ \\
Greater London & $1 \cdot 29(1 \cdot 07-1 \cdot 55)$ & $1 \cdot 10(0 \cdot 90-1 \cdot 35)$ \\
Wales & $1 \cdot 10(0 \cdot 86-1 \cdot 40)$ & $1 \cdot 04(0 \cdot 81-1 \cdot 35)$ \\
Scotland & $0.96(0 \cdot 79-1 \cdot 17)$ & $0 \cdot 86(0 \cdot 70-1 \cdot 06)$ \\
\hline${ }^{a}$ Adjusted for sex, age, social class, marital status, \\
\multicolumn{2}{l}{ nemployment, chronic illness, living environment. } \\
baseline category.
\end{tabular}

appeal and the social class result has a parallel with Townsend's finding that the north-south difference in mortality was less apparent within social classes I and II. ${ }^{28}$

The regional differences in the prevalence of psychiatric morbidity were reduced and no longer statistically significant after adjustment for a number of variables known to be associated with psychiatric morbidity. A more powerful study would be needed to determine whether these explanatory factors could eliminate the regional differences. Among the most important of these factors were living environment and social class.

Table III Odds ratios (95\% confidence intervals) for psychiatric morbidity by region and social class and region and living environment.

\begin{tabular}{|c|c|c|c|c|c|c|}
\hline & \multicolumn{3}{|l|}{ Social class } & \multicolumn{3}{|l|}{ Living environment } \\
\hline & I and II & IIINM and $M$ & $I V$ and $V$ & $\begin{array}{l}\text { Urban, without } \\
\text { open space }\end{array}$ & $\begin{array}{l}\text { Urban, with } \\
\text { open space }\end{array}$ & $\begin{array}{l}\text { Country } \\
\text { district }\end{array}$ \\
\hline $\begin{array}{l}\text { Southern regions } \\
\text { Northern regions } \\
\text { Greater London } \\
\text { Wales } \\
\text { Scotland }\end{array}$ & $\begin{array}{l}1.00^{a} \\
1.00(0.78-1.27) \\
1.21(0.87-1.69) \\
0.94(0.55-1.58) \\
0.85(0.57-1.28)\end{array}$ & $\begin{array}{l}1.00^{a} \\
1.31(1 \cdot 10-1.56) \\
1.14(0.86-1.50) \\
1.36(0.97-1.92) \\
1.01(0.77-1.33)\end{array}$ & $\begin{array}{l}1.00^{a} \\
1.19(0.92-1.53) \\
1.74(1.14-2.65) \\
0.64(0.38-1.06) \\
0.78(0.53-1.17)\end{array}$ & $\begin{array}{l}1.00^{a} \\
1.06(0.85-1.33) \\
1.04(0.79-1.36) \\
0.59(0.36-0.97) \\
1.03(0.75-1.41)\end{array}$ & $\begin{array}{l}1.00^{a} \\
1.24(1.05-1.48) \\
1.19(0.89-1.59) \\
1.35(0.95-1.92) \\
0.80(0.58-1.10)\end{array}$ & $\begin{array}{l}1 \cdot 00^{a} \\
1 \cdot 29(0 \cdot 97-1 \cdot 73) \\
\text { No data } \\
1 \cdot 40(0 \cdot 86-2 \cdot 29) \\
0.90(0 \cdot 59-1 \cdot 39)\end{array}$ \\
\hline
\end{tabular}


There have previously been reports that life in cities is associated with poor mental health ${ }^{29}$ though the characteristics of urban life that lead to this association have not been defined.

Psychiatric morbidity is an important public health problem and these regional differences indicate potential for prevention and have implications for service provision. Though overall there was a strong correlation between mortality and psychiatric morbidity in the British regions, this relationship did not hold for Scotland and Greater London. In the past the provision of health services in London has been determined using mortality as a proxy for need, but the high prevalence of psychiatric morbidity in London may have contributed to the pressure on services and the resulting controversy over the funding of inner city hospitals. ${ }^{30}$

Poor mental health is an important and measurable aspect of morbidity and deserves more attention when public health matters and the distribution of health service resources are discussed.

The study was started while GL was studying for the MSc in Epidemiology at the London School of Hygiene and Tropical Medicine. GL is funded by the Department of Health and MB by the Medical Research Council. Prof Geoffrey Rose gave some helpful comments on an earlier draft. We would also like to thank Lucy Carpenter and Michael Hills for statistical advice.

1 Black D, Morris JN, Smith C, Townsend P. Inequalities in health: the Black Report. Harmondsworth, Middlesex: Penguin, 1982.

Whitehead M. The health divide: inequalities in health in the 1980s. London: Helath Education Authority, 1987.

3 World Health Organization Regional Office for Europe. Targets for health for all. Copenhagen: WHO 1985.

4 Department of Health and Social Security Report of the Resource Allocation Working Party. London: DHSS, 1976. 5 Tessler R, Mechanic D, Dimond $M$. The effect of psychological distress on physician utilization: a

6 Williams P, Tarnopolsky A, Hand D, Shepherd M. Minor psychiatric morbidity and general practice consultations: psychiatric morbidity and general practice consultations:
the West London Survey. Psychol Med 1986; monograph the West
suppl 9.

7 Briscoe ME. Why do people go to their doctor? Sex

differences in the correlates of GP consultation. Soc Sci differences in the corre
Med 1987; 25: 507-13.
8 Shepherd M, Cooper B, Brown AC, Kalton G. Psychiatric illness in general practice. 2nd ed Oxford: Oxford University Press, 1981

9 Goldberg D, Huxley P. Mental illness in the community. London: Tavistock, 1980.

10 Goldberg D. The detection of psychiatric illness by questionnuire. Maudsley Monograph No 21. London: Oxford University Press, 1972

11 Goldberg D, Williams P. A user's guide to the general health questionnaire. Windsor: NFER-Nelson, 1988.

12 Jenkins R. Minor psychiatric disorder in employed young men and women and its contribution to sickness absence. Br F Ind Med. 1985; 42 147-54.

13 Broadhurst WE, Blazer D, George LK, et al. Depression, disability days and days lost from work in a prospective disability days and days lost from work in a pros

14 Croft-Jefferys $\mathrm{C}$, Wilkinson $\mathrm{G}$. Estimated costs of neurotic disorder in UK general practice 1985. Psychol Med 1989; 19: 549-58.

15 Davies LM, Drummond MF. The economic burden of schizophrenia. Psychiat Bull 1990; 14: 522-5.

16 Andrews G, Hall W, Goldstein G, Lapsley H, Bartels R, Silove D. The economic costs of schizophrenia. Arch Gen Psychiatry 1985; 42: 537-43.

17 Goldberg DP, Bridges K. Somatic presentations of psychiatric illness in primary care settings. F Psychosom Res 1988; 32: 137-44.

18 Cox BD, Blaxter M, Buckle ALJ, et al. The health and lifestyle survey. Cambridge: Health Promotion Research Trust, 1987.

19 Office of Population Censuses and Surveys. Classification of occupations. London: HMSO, 1980.

20 Breslow NE, Day NE. Statistical methods in cancer research. Vol II. The design and analysis of cohort studies. Lyon: International Agency for Research on Cancer, 1987.

21 Office of Population Censuses and Surveys. Mortality statistics: area 1984. England and Wales. London: HMSO, 1985.

22 Registrar General Scotland. Annual report 1985. Edinburgh: HMSO, 1986.

23 Statistics and Epidemiology Research Corporation. EGRET, Version 0.22. Seattle, Washington: Statistics and Epidemiology Research Corporation, 1988.

24 Williams P. Macdonald A. The effect of non-response bias on the results of two-stage screening surveys of psychiatric disorder. Soc Psychiatry 1986; 21: 182-6.

25 Clark VA, Aneshensel CS, Frerichs RR, Morgan TM. Analysis of non-response in a prospective study of depression in Los Angeles County. Int $\mathcal{F}$ Epidemiol 1983; 12: $193-8$

26 Rose G. Sick individuals and sick populations. Int $f$ Epidemiol 1985; 14: 32-8.

27 Rose G, Day S. The population mean predicts the number of deviant individuals. BMF 1990; 301: 1031-4.

28 Townsend $\mathrm{P}$, cited in Whitehead $\mathrm{M}$. The health divide: inequalities in health in the 1980's, London: Health Education Council, 1987

29 Blazer DG, George LK, Landerman R, et al. Psychiatric disorders: a rural/urban comparison. Arch Gen Psychiatry 1985; 42: 651-6.

30 Debate on hospitals. House of Commons Official Report (Hansard). 16 June, 1986; 99: cols 750-799 (No 129). 